\title{
Patología infecciosa: vulvovaginitis, enfermedades de transmisión sexual, enfermedad inflamatoria pélvica, abscesos tubo-ováricos
}

\section{Infectious pathology: vulvovaginitis, sexually transmitted diseases, pelvic inflammatory disease, tubo-ovarian abscesses}

\author{
M. Ibarrola, J. Benito, B. Azcona, N. Zubeldía
}

\section{RESUMEN}

Las enfermedades de transmisión sexual son aquellas en las que la principal vía de infección es el contacto íntimo. Son numerosas las pacientes que acuden a urgencias por esta causa, tanto por la clínica como por las implicaciones sociales. Los síntomas más frecuentes son dolor abdominal bajo, sangrados vaginales, o flujo vaginal excesivo o molesto.

Las vulvovaginitis son uno de los problemas principales en la práctica clínica diaria del ginecólogo.

La úlcera genital cuya etiología principal es el herpes, seguida de la sífilis y el chancroide incrementa el riesgo para contraer la infección por el VIH y modifica el curso de otras enfermedades de transmisión sexual.

La enfermedad pélvica inflamatoria engloba a las infecciones del tracto genital superior femenino. La importancia del diagnóstico precoz y su tratamiento adecuado reside tanto por las complicaciones en la fase aguda como por las secuelas, que incluyen el dolor crónico y la esterilidad.

Palabras clave. Enfermedades de transmisión sexual. Vulvovaginitis. Úlcera genital. Enfermedad inflamatoria pélvica.

\begin{abstract}
Sexually transmitted diseases are those where the principal path of infection is through intimate contact. Numerous patients attend Accidents and emergencies for this reason, both because of the clinical features and because of social implications. The most frequent symptoms are lower abdominal pain, vaginal bleeding or excessive or troubling vaginal flow.

Vulvovaginites are one of the principal problems in the everyday clinical practice of gynaecology.

A genital ulcer whose principal aetiology is herpes, followed by syphilis and chancroid, increases the risk of contracting HIV infection and alters the course of other sexually transmitted diseases.

Inflammatory pelvic disease encompasses infections of the upper female genital tract. The importance of early diagnosis and suitable treatment is both due to the complications in its acute phase and to its sequels, which include chronic pain and sterility.
\end{abstract}

Key words. Sexually transmitted diseases. Vulvovaginitis. Genital ulcer. Inflammatory pelvic disease.
Servicio de Obstetricia y Ginecología. Hospital Virgen del Camino. Pamplona
Correspondencia:

María Ibarrola Vidaurre

Servicio de Obstetricia y Ginecología

Hospital Virgen del Camino

Tfno. 650011993

E-mail: mariaibarrolav@hotmail.com 


\section{INTRODUCCIÓN}

Las enfermedades de transmisión sexual (ETS) son aquellas en las que la principal vía de infección es el contacto íntimo, aunque hay ocasiones en que no es el único.

Son numerosas las pacientes que acuden a los servicios de urgencias por esta causa; por lo florido del brote, por la incomodidad de la paciente que demanda una solución rápida y por las implicaciones sociales o riesgo de contagio al compañero sexual. Además si la paciente está embarazada consulta por las consecuencias que pudiera tener para el feto.

Los síntomas más frecuentes son: dolor abdominal bajo, sangrados vaginales, o flujo vaginal excesivo o molesto. Este último síntoma será uno de los principales dentro del cuadro de vulvovaginitis.

Las vulvovaginitis son unos de los problemas principales en la práctica clínica diaria del ginecólogo. Se estima que se alcanzan frecuencias de hasta el $20 \%$ de las mujeres/año a la hora de padecer un proceso infeccioso vulvovaginal.

La úlcera genital representa otro motivo frecuente de atención en urgencias, siendo el herpes la causa más frecuente de ésta, seguida de la sífilis. A su vez, la presencia de úlcera genital supone mayor riesgo para contraer la infección por el VIH y modifica el curso clínico de otras ETS; ahí radica la importancia de un adecuado enfoque desde la asistencia en urgencias.

La enfermedad pélvica inflamatoria (EPI) es el síndrome clínico que engloba a las infecciones del tracto genital superior femenino. Hay que tenerla presente en el diagnóstico diferencial de toda mujer en edad fértil que acude a urgencias con dolor pélvico, llegando a ser la causa de ingreso ginecológico más frecuente, según algunas series. La mayoría son diagnosticadas en mujeres nulíparas entre los 15-24 años.

Es importante el diagnóstico precoz de la EPI y su tratamiento adecuado, tanto por las complicaciones en la fase aguda como por las secuelas. Dentro de las primeras, la más grave es la peritonitis pélvica, siendo en ocasiones necesaria la histerectomía. Las secuelas del proceso agudo y una EPI crónica son infecciones recurrentes, dolor pélvico crónico, adherencias, infertilidad y mayor incidencia de embarazos ectópicos.

\section{VULVOVAGINITIS}

La vulvovaginitis es la inflamación de la vulva, la vagina o ambas estructuras a la vez. Alrededor del $90 \%$ están causadas por cándida, tricomonas o son vaginosis bacterianas.

\section{Vulvovaginitis candidiásica}

La vulvovaginitis candidiásica representa el $25 \%$ de las vaginitis y el $90 \%$ de las mismas. Está producida por Cándida albicans. Se entiende por vulvovaginitis recurrente cuando existen más de cuatro episodios en un año ${ }^{1}$.

La clínica característica es el prurito intenso acompañado de leucorrea blanquecina en forma de grumos y no maloliente. A su vez produce eritema, edema vulvar y dispareunia (Fig. 1).

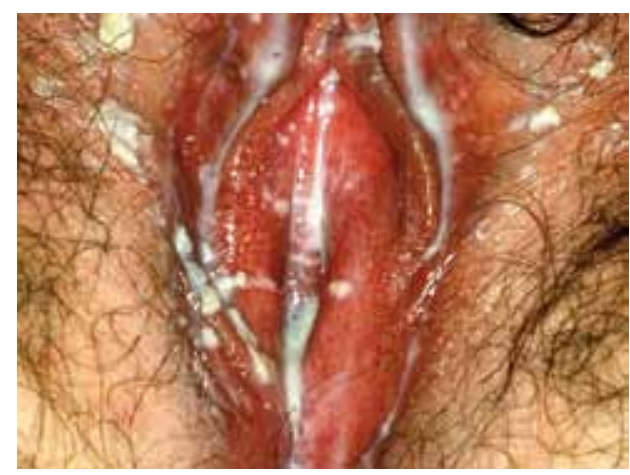

Figura 1. Vulvovaginitis candidiásica.

Para alcanzar el diagnóstico es preciso analizar el PH vaginal que se situará entre 4,2 y 4,7 , igual que en la paciente asintomática. Se realizará un examen en fresco y una segunda extensión con $\mathrm{KOH}$ al 10\% (Test de Whiff) observando hifas. Finalmente puede realizarse una citología cérvicovaginal y cultivos en medio de Saboureaud o medio de Nickerson.

Respecto al tratamiento la vía de administración es opcional y en los casos no complicados puede concertarse con la paciente. El tratamiento tópico suele oscilar 
entre 3-7 días o régimen monodosis (clotrimazol) (Tabla 1). En el tratamiento sistémico se prefiere al fluconazol (150 mg dosis única) y el itraconazol (200 mg/día/1-3días) frente al ketoconazol (200 mg/12h/3-5días) por su hepatotoxicidad. En caso de candidiasis de repetición deben hacerse cultivos, tratar a la pareja sexual y descartar patología concomitante.

Tabla 1. Tratamiento tópico de la candidiasis genital.

\section{Clotrimazol}

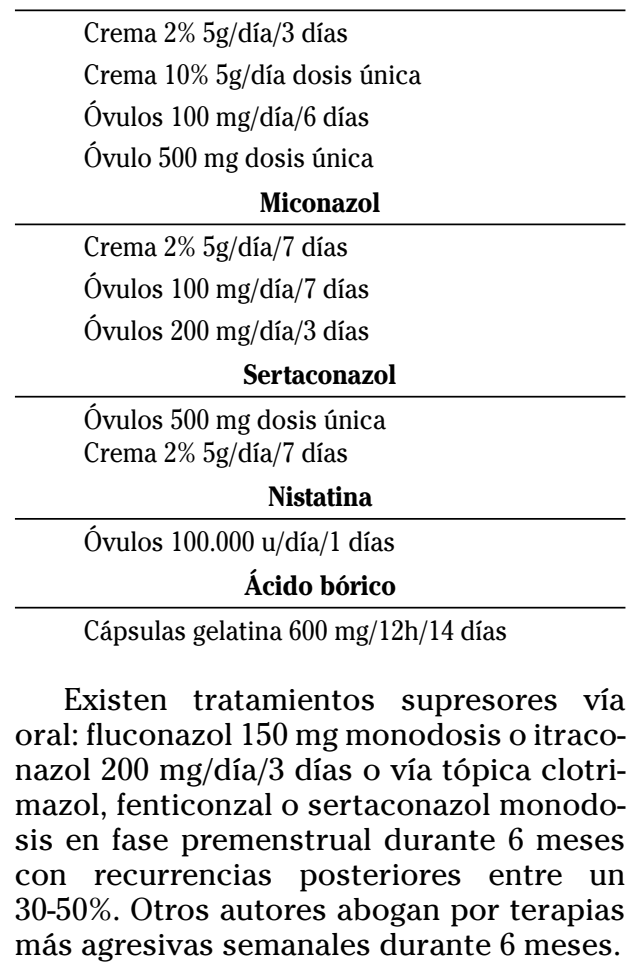

\section{Vaginosis bacteriana}

La vaginosis bacteriana es debida al aumento de Gardnerella vaginalis y otros anaerobios junto con la disminución de Lactobacillus.

Clínicamente es característica la existencia de un flujo maloliente (olor a pescado) de color blanquecino-grisáceo, fluido, homogéneo y en cantidad moderada. En ocasiones se asocia a prurito vulvar, escozor vaginal, sensación de color o ardor y dispareunia.
El diagnóstico se basa en el pH vaginal que oscila entre 5 y 6 , incluso superior. Esto se debe a la desaparición de los bacilos de Döderlein responsables en parte de la acidez vaginal. Se realizará la prueba de las aminas que consiste en aplicar una gota de solución de $\mathrm{KOH}$ al $10 \%$ que produce la volatilización de las aminas, desprendiendo un olor desagradable a pescado. Al examen microscópico destaca la existencia de flora cocobacilar con "clue cells" que son células del epitelio vaginal recubiertas en su superficie por cocobacilos. También puede ayudar al diagnóstico la citología cérvicovaginal.

Para efectuar el diagnóstico de vaginosis bacteriana deben cumplirse 3 de los 4 criterios de Amstel: leucorrea grisácea, acuosa y homogénea, $\mathrm{pH}$ vaginal $>4,5$, test de aminas positivo, presencia de células clave.

En mujeres no gestantes debe tratarse a todas las pacientes sintomáticas o a las asintomáticas que van a ser sometidas a procedimientos quirúrgicos invasivos (biopsia de endometrio, histeroscopia, inserción de DIU o histerectomía). El tratamiento de la pareja sexual no está recomendado.

Las pautas de tratamiento se basan en metronidazol o clindamicina tanto vía oral como tópica (Tabla 2).

Tabla 2. Tratamiento de la vaginosis bacteriana.

Metronidazol $500 \mathrm{mg} \mathrm{vo/12h/7días}$

Metronidazol gel 0,75\% intravaginal diario/5 días

Clindamicina crema $2 \% 5 \mathrm{~g}$ intravaginal diaria/7días

Clindamicina $300 \mathrm{mg}$ vo/12h/7días

Clindamicina óvulos vaginales $100 \mathrm{mg}$ diario

\section{Tricomoniasis}

La Trichomona vaginalis es un parásito protozoario anaerobio. Tiene su ubicación de forma única en el tracto genital. Constituye el $15-20 \%$ de todas las vaginitis ${ }^{2}$.

La clínica se caracteriza por la existencia de una secreción vaginal profusa, abundante, de color gris-amarillento-verdoso, fluida, espumosa y maloliente. El cuadro 
suele cursar con prurito genital, escozor, disuria y dispareunia, aunque puede ser asintomático en el 10-50\% de los casos.

En la exploración destaca una vulvitis y enrojecimiento de la mucosa vaginal. El cérvix se muestra congestivo y friable, en "frambuesa" y al examen colposcópico es típica una colpitis a puntos rojos.

Para alcanzar el diagnóstico ${ }^{3}$ debe realizarse un $\mathrm{pH}$ vaginal que será superior a 5 $(5-6,5)$ y un examen en fresco visualizando al parásito móvil y flagelado, de mayor tamaño a los leucocitos acompañado de gran cantidad de polimorfonucleares. También aportará información la realización de tinción Giemsa, citología cérvicovaginal y cultivos de Trichicult o Diamond.

El tratamiento debe ser simultáneo en la pareja. Las pautas de tratamiento son metronidazol $2 \mathrm{~g}$ vo dosis única o metronidazol $500 \mathrm{mg} / 12 \mathrm{~h} / 7$ días o tinidazol $2 \mathrm{~g}$ vo dosis única (Tabla 3).

Tabla 3. Vulvovaginitis. Diagnóstico diferencial.

\begin{tabular}{|c|c|c|c|}
\hline & Candidiasis & Vaginosis bacteriana & Tricomoniasis \\
\hline Agente etiológico & $90 \%$ C. albicans & $\begin{array}{c}\text { Aumento Gardnerella } \\
\text { vaginalis y otros } \\
\text { anaerobios }\end{array}$ & Trichomona vaginalis \\
\hline Clínica & $\begin{array}{l}\text { Prurito con leucorrea } \\
\text { blanca no maloliente }\end{array}$ & $\begin{array}{l}\text { Prurito, escozor, ardor. } \\
\text { Flujo maloliente } \\
\text { blanco-grisáceo fluido }\end{array}$ & $\begin{array}{c}\text { Prurito, disuria, } \\
\text { dispareunia. } \\
\text { Secrección vaginal } \\
\text { profusa, gris amarillenta, } \\
\text { maloliente y espumosa. }\end{array}$ \\
\hline $\mathrm{pH}$ & $4,2-4,7$ & $5-6$ & $5-6,5$ \\
\hline Frotis en fresco & Hifas $80 \%$ & "Clue cells" 97\% & Parasito móvil flagelado \\
\hline Tratamiento & $\begin{array}{l}\text { Tópico u oral con } \\
\text { antimicóticos }\end{array}$ & $\begin{array}{l}\text { Tópico u oral con } \\
\text { metronidazol o } \\
\text { clindamicina }\end{array}$ & $\begin{array}{l}\text { Oral } \\
\text { Metronidazol o tinidazol }\end{array}$ \\
\hline
\end{tabular}

\section{Úlcera genital}

La úlcera genital representa otro motivo de atención en urgencias mayoritariamente en pacientes jóvenes sexualmente activas. La frecuencia y etiología difiere según el área geográfica, aunque es el herpes la causa más frecuente de ésta, seguida de la sífilis y el chancroide (Tabla 4). A su vez la presencia de úlcera genital supone un incremento del riesgo para contraer la infección por el VIH. No todas las úlceras genitales están causadas por infecciones de transmisión sexual.

\section{Infección herpética genital}

Está causada por el virus Herpes simplex (VHS). Generalmente por VHS-2, aunque aumenta la frecuencia de herpes genital por VHS-1. Dicha ETS es la causa más frecuente de úlcera genital en los países desarrollados.

La transmisión tiene lugar por contacto personal estrecho, generalmente sexual y puede acontecer en periodos de excreción asintomática.

La infección primaria tiene un período de incubación de 2 a 12 días, seguido de pródromos como quemazón, dolor y eritema. Después aparecen múltiples vesículas dolorosas que se ulceran en la región perineal o perianal, vulva, vagina o cérvix, a veces con linfadenopatía inguinal muy dolorosa y raramente supurativa. Espontáneamente se forma una costra y la úlcera cura a los 14 ó 21 días. A menudo se acompaña de síntomas sistémicos, con fiebre, cefalea, mal estado general, mialgias y dolor abdominal. Episódicamente el virus suele reactivarse ocasionando enfermedad recurrente con sintomatología local más limitada y sin clínica sistémica (Fig. 2). 
Tabla 4. Úlcera genital. Diagnóstico diferencial.

\begin{tabular}{|c|c|c|c|c|c|}
\hline & Herpes genital & $\begin{array}{l}\text { Chancro blando } \\
\text { o chancroide }\end{array}$ & $\begin{array}{c}\text { Granuloma } \\
\text { inguinal o } \\
\text { donovanosis }\end{array}$ & $\begin{array}{l}\text { Linfogranuloma } \\
\text { venéreo }\end{array}$ & Sífilis primaria \\
\hline $\begin{array}{l}\text { Período } \\
\text { incubación }\end{array}$ & 2-12 días & 1 semana & Varias semanas & 1-4 semanas & 1-2 semana \\
\hline Agente etiológico & VHS 2 y 1 & H. ducreyi & C. granulomatis & $\begin{array}{l}\text { C. trachomatis (L1, } \\
\text { L2, L3) }\end{array}$ & $\begin{array}{l}\text { Treponema } \\
\text { pallidum }\end{array}$ \\
\hline Tamaño & $1-3 \mathrm{~mm}$ & $2-20 \mathrm{~mm}$ & & $2-10 \mathrm{~mm}$ & $5-15 \mathrm{~mm}$ \\
\hline Úlcera & $\begin{array}{l}\text { Superficial, } \\
\text { eritematosa no } \\
\text { indurada }\end{array}$ & $\begin{array}{l}\text { Profunda, } \\
\text { desigual,base } \\
\text { purulenta }\end{array}$ & $\begin{array}{l}\text { Progresa hacia } \\
\text { región inguinal }\end{array}$ & $\begin{array}{l}\text { Elevada, redonda, } \\
\text { profundidad } \\
\text { variable }\end{array}$ & $\begin{array}{l}\text { Margen elevado, } \\
\text { lisa, base } \\
\text { necrótica, } \\
\text { induración firme }\end{array}$ \\
\hline $\begin{array}{l}\text { Número de } \\
\text { lesiones }\end{array}$ & Múltiples & $\begin{array}{l}\text { Normalmente de } \\
1 \text { a } 3\end{array}$ & Una & Una & Una \\
\hline Dolor & Dolor y quemazón & Dolorosa & Indolora & Indolora & $\begin{array}{l}\text { Indolora o poco } \\
\text { dolorosa }\end{array}$ \\
\hline Adenopatía & $\begin{array}{l}\text { Bilaterales, muy } \\
\text { dolorosas }\end{array}$ & $\begin{array}{l}\text { Bubas unilaterales } \\
\text { dolorosas, } \\
\text { adheridas a la piel } \\
\text { y fistulizan sin } \\
\text { tratamiento }\end{array}$ & Ausencia & $\begin{array}{l}\text { Unilateral, } \\
\text { dolorosa, adherida } \\
\text { a piel y puede } \\
\text { fistulizar }\end{array}$ & $\begin{array}{l}\text { Bilaterales e } \\
\text { indoloras }\end{array}$ \\
\hline Diagnóstico & $\begin{array}{l}\text { Clínica+Cultivo } \\
\text { celular }\end{array}$ & $\begin{array}{l}\text { Clínica+Gram+ } \\
\text { Cultivo+Inmun. } \\
\text { Indirecta+ Biopsia }\end{array}$ & $\begin{array}{l}\text { Clínica+ } \\
\text { Giemsa+Biopsia }\end{array}$ & $\begin{array}{l}\text { Clínica + } \\
\text { Cultivo+Inmun. } \\
\text { Directa+ Biopsia } \\
\end{array}$ & $\begin{array}{l}\text { Examen directo en } \\
\text { campo oscuro } \\
\text { Serología }\end{array}$ \\
\hline Tratamiento & $\begin{array}{l}\text { Aciclovir } \\
\text { Valaciclovir } \\
\text { Famciclovir } \\
\text { Primoinfección } \\
\text { 7-10 días } \\
\text { Recidivas } 5 \text { días }\end{array}$ & $\begin{array}{l}\text { Azitromicina 1gvo } \\
\text { Ceftriaxona 250mg } \\
\text { im } \\
\text { Dosis única }\end{array}$ & $\begin{array}{l}\text { Doxiciclina } 100 \\
\text { mg/12/3 semanas }\end{array}$ & $\begin{array}{l}\text { Doxiciclina } 100 \\
\mathrm{mg} / 12 / 21 \text { días } \\
\text { Eritromicina } 500 \\
\mathrm{mg} / 6 \mathrm{~h} / 21 \text { días }\end{array}$ & $\begin{array}{l}\text { Penicilina } \\
\text { benzatina 2,4M im } \\
\text { dosis única }\end{array}$ \\
\hline
\end{tabular}

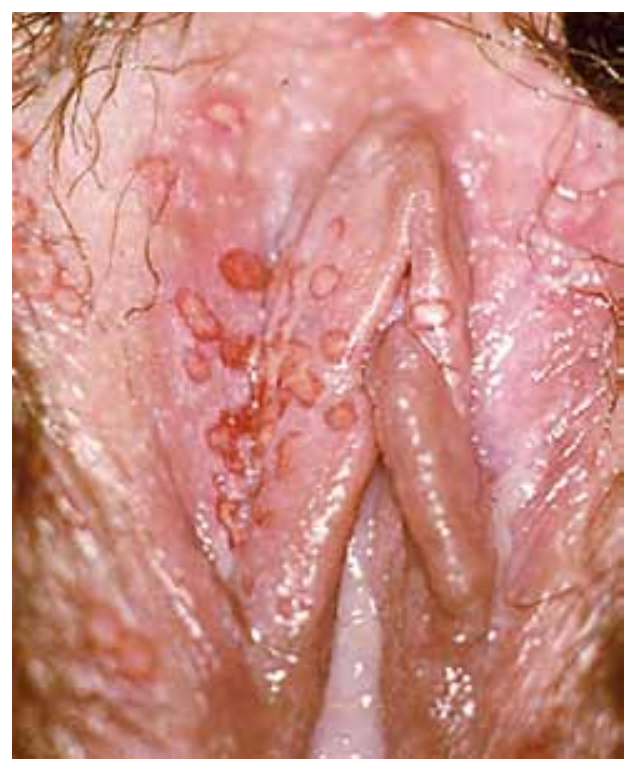

Figura 2. Herpes genital.
El diagnóstico se basa en la clínica, el aislamiento viral y tipificación de muestras, siendo el método de elección para el diagnóstico, tomar material de la vesícula o realizar un raspado sobre el fondo de la úlcera. Existen análisis complementarios con detección directa de antígenos, técnicas moleculares y serología.

El tratamiento de los episodios se administra para reducir los síntomas y la infectividad, sin que influya en la frecuencia de recurrencias posteriores ${ }^{4}$.

En el tratamiento del primer episodio se aconseja la revisión de los compañeros sexuales y si son sintomáticos deben ser tratados como la pareja con aciclovir 400 $\mathrm{mg} / 8 \mathrm{~h} / 7-10$ días o $200 \mathrm{mg} / 5$ veces al día/710días o valaciclovir $1 \mathrm{~g} / 12 \mathrm{~h} / 7-10$ días o famciclovir $250 \mathrm{mg} / 8 \mathrm{~h} / 7-10$ días.

El tratamiento de las recurrencias sólo es efectivo cuando se inicia en fase prodrómica o tras 1 día de aparición de las vesícu- 
las. En ocasiones no es necesario al ser cuadros leves. Las pautas recomendadas son aciclovir $400 \mathrm{mg} / 8 \mathrm{~h} / 5$ días ó $800 \mathrm{mg} / 12 \mathrm{~h} / 5$ días o $800 \mathrm{mg} / 8 \mathrm{~h} / 2$ días o valaciclovir 500 $\mathrm{mg} / 12 \mathrm{~h} / 3$ días ó $1 \mathrm{~g} / 24 \mathrm{~h} / 5$ días o famciclovir $125 \mathrm{mg} / 12 \mathrm{~h} / 5$ días ó $1 \mathrm{~g} / 12 \mathrm{~h} / 1$ día.

\section{Chancroide o chancro blando}

Es una infección por Haemophilus ducre$y i$, cofactor para la transmisión del VIH. El periodo de incubación es de una semana. Es una infección propia de países tropicales y subtropicales.

La clínica se caracteriza por una úlcera genital dolorosa de bordes blandos que sangra fácilmente acompañada de "bubas", adenopatías que aparecen 5-7 días más tarde que la úlcera. Éstas son unilaterales, inflamatorias, dolorosas, adheridas a la piel y fistulizan 7-10 días más tarde si no se trata la infección.

El diagnóstico se basa en la clínica; la tinción Gram observando estreptobacilos Gram negativos aunque su negatividad no excluye el diagnóstico; el cultivo en medio de Borchardt; la inmunofluorescencia indirecta y la biopsia de la lesión.

Las pautas de tratamiento recomendadas incluyen el tratamiento de la pareja con azitromicina $1 \mathrm{~g}$ vo dosis única o ceftriaxona $250 \mathrm{mg}$ im dosis única.

\section{Granuloma inguinal (Donovanosis)}

Es una infección rara en nuestro medio producida por Calymmatobacterium granulomatis. Procede de países tropicales y es más frecuente en hombres.

La enfermedad cursa con una úlcera indolora en vulva, vagina o cérvix que progresa hacia región inguinal sin adenopatías regionales y con lesiones sangrantes al roce.

El diagnóstico se alcanza a través de la clínica, la realización de tinción Giemsa observando los corpúsculos de Donovan (células mononucleares que contienen vacuolas encapsuladas donde se encuentran las bacterias) y la biopsia. El tratamiento se basa en doxiciclina $100 \mathrm{mg} / 12 \mathrm{~h} / 3$ semanas

\section{Linfogranuloma venéreo}

Entidad producida por Chlamydia trachomatis (L1, L2 y L3). Dicha afección se caracteriza por una fase primaria tras el periodo de incubación de 1-4 semanas. Aparece una pequeña pápula o úlcera indolora. La fase secundaria tiene lugar a las 1-3 semanas tras la curación de la úlcera y aparecen adenopatías unilaterales adheridas a la piel y que pueden fistulizar. Finalmente la fase terciaria o destructiva en casos no tratados cursa con el característico síndrome anorrectogenital.

El diagnóstico se basa en la clínica, cultivo celular, inmunofluorescencia directa y biopsia. El tratamiento se basa en la doxiciclina $100 \mathrm{mg} / 12 \mathrm{~h} / 21$ días o eritromicina $500 \mathrm{mg} / 6 \mathrm{~h} / 21$ días, pauta recomendada en gestantes.

\section{Sífilis}

Enfermedad infecciosa sistémica producida por una espiroqueta, el Treponema pallidum.

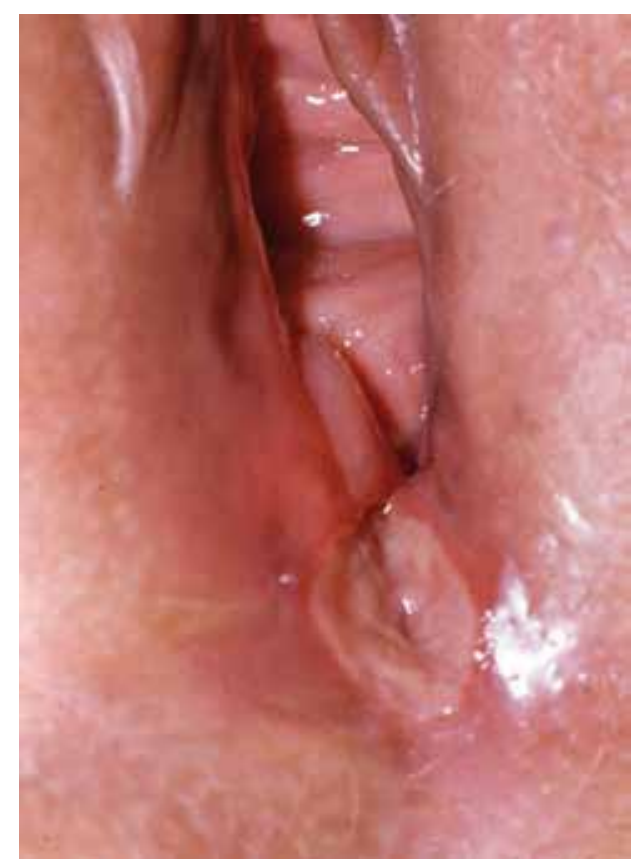

Figura 3. Úlcera sifilítica.

La sífilis primaria se caracteriza por la aparición del chancro, una lesión solitaria e indolora, de consistencia indurada, con base limpia, no purulenta y exudación amarillo-grisácea, que aparece en el sitio de ino- 
culación unas 3 semanas (9-90 días) tras la exposición. El chancro puede aparecer en la vulva, en el fondo del saco vaginal posterior o en el cérvix, aunque en un $5 \%$ de los casos su localización puede ser extragenital. Suelen existir adenopatías bilaterales e indoloras. Este cuadro cede espontáneamente a los 10-14 días. El 50\% de las pacientes no tratadas desarrollarán sífilis secundaria y la otra mitad sífilis latente (Fig. 3).

La sífilis secundaria llamada "la gran simuladora" aparece 6-8 semanas después. Suele aparecer un cuadro de malestar general, fiebre, mialgias, rinorrea, adenopatías generalizadas y un exantema máculopapuloso no puriginoso en tronco con extensión a extremidades y afectación palmo-plantar. Posteriormente existe un collarete de descamación periférica de las lesiones acompañado de los "clavos sifilíticos" en palmas y plantas, de alopecia en placas y "condilomas planos" en regiones intertriginosas. Sin tratamiento el cuadro se resuelve espontáneamente a las 2-12 semanas entrando en periodo de latencia, pero un tercio de las pacientes desarrollarán sífilis terciaria con afectación mucocutánea, ósea, visceral o neural ${ }^{5}$.

El diagnóstico se basa en dos pilares, el examen directo y las pruebas serológicas. El examen directo mediante la observación directa en campo oscuro de los treponemas móviles. Es el único método seguro. Sólo es posible en sífilis primaria y en lesiones secundarias con ulceraciones mucocutáneas ${ }^{6}$. Por otro lado, las pruebas serológicas necesarias para el resto de los estadios y el seguimiento. Éstas pueden ser negativas inicialmente por lo que deben repetirse semanalmente. Existen las pruebas inespecíficas o reagínicas VDRL y RPR para cribado, seguimiento de la enfermedad y estudio de afectación del SNC, y las pruebas específicas o antitreponémicas para confirmación del diagnóstico.

El tratamiento de la sífilis primaria, secundaria o latente de menos de un año de evolución, típica de la consulta de urgencias, se basa en penicilina benzatina 2,4 M UI im dosis única y en alérgicos a penicilina podría emplearse doxiciclina 100 $\mathrm{mg} \mathrm{vo} / 12 \mathrm{~h} / 14$ días o eritromicina $500 \mathrm{mg}$ vo/6h/14 días excepto en embarazadas que sería necesaria la desensibilización a la penicilina.

\section{Cervicitis}

La cervicitis se caracteriza por un exudado purulento endocervical, motivo de consulta en urgencias. En la exploración el cérvix sangra fácilmente al roce con una torunda. Con frecuencia las cervicitis son asintomáticas, pero otras veces cursan con leucorrea y sangrados intercíclicos coincidentes con las relaciones sexuales ${ }^{7}$.

Ante la sospecha de cervicitis y existencia de factores de riesgo se administrará tratamiento de forma empírica. Clásicamente la cervicitis está producida por $C$. trachomatis y $N$. gonorrhoeae.

\section{Infecciones por Chlamydia trachomatis}

Es una de las ETS más frecuentes. Tres síndromes que se asocian a $C$. trachomatis son comunes: cervicitis mucopurulenta, uretritis y enfermedad inflamatoria pélvica.

El diagnóstico se basa en el cultivo celular en células de McCoy o HeLa. También puede emplearse la detección de antígenos por inmunofluorescencia directa o enzimoinmunoanálisis. Otras técnicas más recientes incluyen la amplificación de gen mediante PCR.

El tratamiento de elección es azitromicina $1 \mathrm{~g}$ vo dosis única (de elección en embarazo) o doxiciclina $100 \mathrm{mg} / 12 / 7$ días. También existen pautas alternativas con eritromicina, ofloxacino o levofloxacino.

\section{Infecciones por gonococo}

Neisseria gonorrhoeae es la bacteria que produce la gonorrea, segunda ETS bacteriana más importante en la actualidad. Produce cervicitis, EPI, uretritis, proctitis y orofaringitis.

El cuadro más grave es la bacteriemia gonocócica que cursa con petequias y pústulas en regiones acras, artralgia asimétrica, sinovitis y artritis séptica, incluso puede producir perihepatitis y en raras ocasiones meningitis y endocarditis.

La mayoría de los pacientes infectados con $N$. gonorrhoeae están coinfectados con C. trachomatis por lo que el tratamiento deberá cubrir a ambas. 
Ante la sospecha clínica se tomarán muestras de fondo de saco vaginal, endocérvix, uretra, recto y faringe para realización de tinción Gram. También es necesario hacer cultivo en medio de Thayer-Martin ya que su sensibilidad es mayor. Como el gonococo es muy sensible al medio externo y sólo resiste de 2 a 6 horas fuera del organismo humano se debe remitir rápidamente al laboratorio. Otra forma de llegar al diagnóstico es mediante enzimoinmunoanálisis.

El tratamiento de las infecciones no complicadas de cérvix, uretra y recto incluye ceftriaxona $125 \mathrm{mg}$ im dosis única o cefixima $400 \mathrm{mg}$ vo dosis única o ciprofloxancino $500 \mathrm{mg}$ vo dosis única o ofloxacino 400 $\mathrm{mg}$ vo dosis única o levofloxacino $250 \mathrm{mg}$ vo dosis única. Como pauta alternativa está una dosis única de $2 \mathrm{~g}$ de espectinomicina.

\section{Enfermedad inflamatoria pélvica}

La EPI forma el conjunto de alteraciones inflamatorias de tracto genital femenino que incluyen: endometritis, salpingitis, absceso tubo-ovárico y peritonitis pelviana. Estas alteraciones se producen por el ascenso de microorganismos desde el cérvix hacia el interior.

En la mayoría de los casos son responsables $N$. gonorrhoeae o $C$. trachomatis aunque microorganismos que forman parte de la flora normal pueden producir EPI, como es el caso de $G$. vaginalis, $H$ influenzae, bacilos Gram negativos entéricos, etc.

En la práctica clínica se debe descartar la existencia de EPI cuando una mujer sexualmente activa presenta dolor pélvico acompañado de fiebre y leucorrea, aunque tanto la fiebre como la leucorrea se presenta sólo en la mitad de los casos.

La estadificación clínica se divide en cuatro estadios ${ }^{8}$ :

1. Estadio I, salpingitis aguda sin pelviperitonitis

2. Estadio II, salpingitis aguda con pelviperitonitis

3. Estadio III, salpingitis con formación de abscesos tubo-ováricos

4. Estadio IV, rotura de absceso tuboovárico, cuadro muy grave que da lugar a una peritonitis generalizada.
Ante la sospecha de EIP debe realizarse una exploración abdominal donde puede observarse cierta distensión abdominal y en ocasiones Blumberg positivo. Debe realizarse una inspección de genitales externos en busca de estigmas de ETS. Mediante especuloscopia se podrá valorar vagina y cérvix en búsqueda de signos de inflamación y leucorrea y se tomarán muestras endocervical y vaginal para tinción Gram, frotis en fresco y cultivos microbiológicos.

La exploración abdominovaginal puede provocar dolor a la movilización cervical y a la presión de Douglas. La palpación de anejos es dolorosa y pueden palparse engrosados ${ }^{9}$.

Se realizará un hemograma con VSG o PCR, toma de temperatura y será preciso descartar la gestación. La ecografía transvaginal es una exploración fundamental que puede ser normal u observar engrosamientos anexiales, dilataciones tubáricas, exudado peritoneal, abscesos pélvicos.

Los criterios diagnósticos de Centre for Disease Control (CDC) 2006 se dividen en criterios mínimos que incluirían dolor uterino o anexial o dolor a la movilización cervical y criterios adicionales para aumentar la sensibilidad como la temperatura superior $38,3^{\circ} \mathrm{C}$, leucorrea anormal vaginal o cervical, leucocitosis en el frotis en fresco vaginal, aumento de VSG o PCR y la evidencia en laboratorio de $N$. gonorrhoeae o $C$. trachomatis en endocérvix.

Entre los diagnósticos diferenciales hay que destacar la apendicitis aguda, el embarazo ectópico, el quiste de ovario torsionado, rotura de teratoma o endometrioma, perforación de divertículo de Meckel, la trombosis venosa mesentérica y el síndrome del shock tóxico.

El tratamiento se iniciará tan pronto como se sospeche la existencia de EIP y deberá cubrir $N$. gonorrhoeae, C.trachomatis $\mathrm{y}$ en determinados casos otros gérmenes anaerobios. Si existen criterios de gravedad la paciente quedará hospitalizada y el tratamiento antibiótico será vía parenteral y en caso contrario podrá realizarse un tratamiento ambulatorio vía oral (Tabla 5). 
Tabla 5. Tratamiento enfermedad inflamatoria pélvica.

\begin{tabular}{|c|c|}
\hline Régimen de ingreso & Régimen ambulatorio \\
\hline $\begin{array}{c}\text { Régimen A } \\
\text { Cefoxitina } 2 \mathrm{~g} \text { IVcada } 6 \text { horas } \\
\text { o bien cefotetan } 2 \mathrm{~g} \text { IV cada } 12 \text { horas } \\
+ \\
\text { Doxiciclina } 100 \mathrm{mg} \text { cada } 12 \text { horas } \\
\text { Régimen B } \\
\text { Clindamicina } 900 \mathrm{mg} \text { IV cada } 8 \text { horas } \\
+ \\
\text { Gentamicina dosis inicial } 2 \mathrm{~g} / \text { Kg peso seguida } \\
\text { de una dosis de } 1,5 \mathrm{mg} / \text { Kg cada } 8 \text { horas } \\
\text { Régimen alternativo } \\
\text { Ampicilina + doxiclina } \\
\text { o } \\
\text { Ofloxacin + clindamicina } \\
\text { o } \\
\text { metronidazol }\end{array}$ & $\begin{array}{l}\text { Régimen A } \\
\text { Cefoxitina } 2 \mathrm{~g} \text { IM + probenecid lgr vía oral } \\
\text { o bien ceftriaxona } 250 \mathrm{mg} \text { IM } \\
\text { u otra cefalosporina de tercera generación } \\
+ \\
\text { Doxiciclina } 100 \mathrm{mg} \text { oral } \\
2 \text { veces al día durante } 14 \text { días } \\
\text { Régimen B } \quad \text { Ofloxacino } 400 \text { mg vía oral } \\
2 \text { veces al día } 14 \text { días } \\
+ \\
\text { Clindamicina } 450 \text { mg oral } 4 \text { veces al día } \\
\text { o } \\
\text { metronidazol } 500 \text { mg oral } 2 \text { veces al dia } \\
\text { durante } 14 \text { días }\end{array}$ \\
\hline
\end{tabular}

El tratamiento quirúrgico debe tenerse en cuenta en casos severos o cuando exista evidencia de absceso tubo-ovárico bilateral o mayor de $8 \mathrm{~cm}$. También puede recomendarse la cirugía tras el fallo al tratamiento médico tras 48-72h

Las parejas sexuales deberán recibir evaluación y tratamiento cuando haya habido un contacto íntimo los 60 días previos al diagnóstico.

\section{OTRAS INFECCIONES}

Existen otras infecciones que ocasionalmente son motivo de urgencia ginecológica destacando la pediculosis pubis conocida popularmente como ladilla, el Molluscum contagiosum que puede afectar al área genital y las verrugas genitales. Dichas entidades, aunque no se pueden considerar un cuadro urgente en cuanto a su gravedad y necesidad de tratamiento inmediato, ocasionan un signo de alerta a la paciente acudiendo por este motivo a urgencias.

\section{Pediculosis}

Es causada por Pthirus pubis y se transmite por contacto íntimo. En adultos se parasita el vello pubiano, aunque en personas hirsutas la extensión puede hacerse a todo el vello corporal, también puede parasitar cejas y pestañas. El síntoma principal es el prurito, que puede ocasionar lesiones de rascado.

El diagnóstico es clínico por la visualización de los parásitos y de sus huevos. El tratamiento incluye permetrina al $1 \%$ en crema en zonas pilosas afectadas, lavando 10 minutos más tarde; el tratamiento se repite a los $4-7$ días $^{10}$.

\section{Molluscum contagiosum}

El agente etiológico es un virus ADN de la familia Poxviridae.

Produce pápulas umbilicadas de 3 a 7 $\mathrm{mm}$. La transmisión sexual se produce en el $60 \%$ de los casos y las lesiones aparecen en región vulvar, perineal, cara interna de muslos o bajo vientre. El tratamiento consiste en la exéresis de las lesiones, cauterización, crioterapia o aplicación de ácido tricloracético.

\section{Verrugas genitales}

La infección genital por Papilomavirus serotipos 6 y 11 , se transmite por contacto sexual, aunque también puede transmitirse perinatalmente y por fómites. 
Las lesiones aparecen en zonas que se han traumatizado durante la relación sexual y pueden ser únicas o múltiples. Habitualmente aparecen entre 5 y 15 lesiones con un diámetro de 1 a $10 \mathrm{~mm}$. Otras veces dan lugar a grandes placas por crecimiento de las diversas lesiones, sobre todo en pacientes inmunosuprimidos $\mathrm{y}$ diabéticos.

En mujeres, las lesiones afectan labios mayores y menores, clítoris, meato uretral, periné, zona anal, vestíbulo, introito, vagina y ectocérvix.

El tratamiento médico de las verrugas genitales externas ${ }^{11}$ se basa en podofilotoxina, crema al $0,15 \%$, o solución al $0,5 \%$, aplicándolo 2 veces al día, durante 3 días; se descansa 4 días y si no han desaparecido, se repite el tratamiento. Se puede repetir los ciclos de tratamiento en 4 ocasiones. El área tratada no debe ser mayor de 10 $\mathrm{cm}^{2}$. O bien puede aplicarse imiquimod, en crema al 5\%, con el dedo tres noches a la semana, lavándolo por la mañana. El tratamiento se hace durante 16 semanas como máximo.

La cirugía puede tener un papel en esta entidad a través de la electrocoagulación, el láser o la escisión de las lesiones. Otros tratamientos se basan en la crioterapia con nitrógeno líquido y el ácido tricloroacético. Finalmente se aconseja le exploración genital y anal de la pareja sexual.

\section{BIBLIOGRAFÍA}

1. CarReras R, López-Yarto M. Vulvovaginitis candidiásica. Folia Clin Obstet Ginecol 2006; 57 Supl 1: S1-S20.

2. KENT HL. Epidemiology of vaginitis. Am J Obstet Gynecol 1991; 165 (4 Pt 2): 1168-1176.

3. OWEN MK, CLENNEY TL. Management of vaginitis. Am Fam Physician 2004; 170: 2125-2132.

4. CDC. Sexually transmitted diseases treatment guidelines 2006. Centres for Disease Control and Prevention. MMWR Recomm Rep 2006; 55: 1-95.

5. Sexually transmitted diseases. Med Clin North Am 1990; 74: 1339-1660.

6. GoLDSMITH MF. Target: sexually transmitted diseases. JAMA 1990; 264: 2179-2180.

7. Farage MA, Miller KW, Ledger WJ. Determining the cause of vulvovaginal symptoms. Obstet Gynecol Surv 2008; 63: 445-464.

8. Documento de Consenso SEGO 2004. Enfermedad inflamatoria pélvica.

9. Royal collage of obstetricians and gynaecologist. Management of acute pelvic inflammatory disease. № 32,$2003 ; 1-9$.

10. Buntin DM, Roser T, Lesher JL JR, PlotNick H, BRAdemas ME, Berger TG. Sexually transmitted diseases:viruses and ectoparasites. Committee on Sexually Transmitted Diseases of the American Academy of Dermatology. J Am Acad Dermatol 1991; 25: 527-534.

11. Krogh G, Lacey CJN, Gross G, Barrasso R, Schner DER. A. European course on HPV associated pathology: guidelines for primary care physicians for the diagnosis and management of anogenital warts. Sex Transm Inf 2000; 76: 162-168. 